\title{
Spontaneous One-Lung Ventilation Increases the Lung Inflammatory Response: An Experimental Pilot Study
}

\author{
Humberto S Machado ${ }^{1 *}$, Paula Sá1, Catarina S Nunes ${ }^{2}$, António Couceiro $^{3}$, Álvaro Moreira da Silva ${ }^{4}$ and Artur Águas ${ }^{5}$
}

${ }^{1}$ Anesthesiology Department, Centro Hospitalar do Porto, Largo Abel Salazar, 4099-001 Porto, Portugal

${ }^{2}$ Open University, Department of Science and Technology and Anesthesiology Department, Centro Hospitalar do Porto, Largo Abel Salazar, 4099-001 Porto, Portugal

${ }^{3}$ Pathological Anatomy service, Gaia/Espinho Hospital Centre, Rua Conceição Fernandes, 4430 Vila Nova de Gaia, Portugal

${ }^{4}$ Intensive care Service, Port Hospital Center, Largo Abel Salazar, 4099-001 Porto, Portugal

${ }^{5}$ Department of Normal Anatomy, Abel Salazar Biomedical Sciences Institute-University of Porto and Multidisciplinary Biomedical Research Unit, St. Jorge Viterbo Ferreira, 228, 4050-313 Porto, Portugal

\begin{abstract}
Study objective: The purpose of this study was to investigate if spontaneous one-lung ventilation would induce any type of inflammatory lung response when compared to spontaneous two-lung ventilation and its intensity, by quantification of inflammatory cells in lung histology at the end of the procedure.
\end{abstract}

Design: In vivo prospective randomised animal study

Setting: University research laboratory

Subjects: New Zealand rabbits

Interventions: Rabbits $(n=20)$ were randomly assigned to 4 groups $(n=5$ each group). Groups 1 and 2 were submitted to one-lung ventilation, during 20 and 75 minutes respectively; groups 3 and 4 were submitted to two-lung ventilation during 20 and 75 minutes and considered controls. Ketamine/xylazine was administered for induction and maintenance of anesthesia. One-lung ventilation was achieved by administration of air into the interpleural space, and left lung collapse was visually confirmed through the centre of the diaphragm.

Measurements: Lung histology preparations were observed under light microscopy for quantification of the inflammatory response (light, moderate and severe).

Main results: All subjects had at least light inflammatory response. However, rabbits submitted to one-lung ventilation had a statistically significant value for the occurrence of moderate inflammation $(p<0.05)$. The inflammatory response found included mainly eosinophils, with an average proportion of 75/25 to other polymorphonuclear cells. No differences between groups were found regarding gas exchange, heart rate and respiratory rate.

Conclusions: In this spontaneous one-lung ventilation model, lung collapse was positively associated with a greater inflammatory response when compared to normal two-lung ventilation.

Keywords: Inflammatory response; One-lung ventilation; Atelectasis

\section{Introduction}

Pulmonary complications such as infection and acute lung injury (ALI) may lead to high morbidity rates after thoracic surgery and/or one-lung ventilation (OLV) [1,2]. Inflammation after lung surgery is pointed out as an important cause for the development of ALI $[3,4]$. The incidence of ALI varies from 2, $5 \%$ in patients submitted to thoracic surgery in general to $7,9 \%$ of patients submitted to pneumonectomy [5]. During thoracic surgery several factors can lead to the release of pro-inflammatory mediators (with the subsequent activation of neutrophils that alter endovascular permeability), namely overdistension, hypoxia, hyperoxia and possibly isquemia-reperfusion injury [6]. Also, mechanical ventilation by itself may induce several alveolar changes which are not seen during spontaneous ventilation [6]. In addition, surgical manipulation of the lung may aggravate the alveolar injury with leukocyte recruitment in both lungs during OLV [6]. These findings support the multiple hit hypotheses, in which lung damage during thoracic surgery may be due to: mechanical ventilation, OLV, surgical manipulation, lung overdistension, atelectrauma and reexpansion/reperfusion injury [7]. However, as far as we know, there are no reported studies that show an independent effect of OLV on lung inflammatory response. Thus, in an experimental controlled animal model with spontaneous ventilation, we hypothesized that lung inflammatory response is not increased by one-lung ventilation itself.

\section{Materials and Methods}

\section{Animals}

The experimental protocol used in this study was approved by the ethics committee, and carried out according to the European Union Directive no 63/2010/EU. Twenty adult New Zealand rabbits were purchased from a Portuguese breeder (NORLAP-Rui M.S. Gonçalo, 4825-466 Água-Longa, Portugal) and kept under standard housing conditions with unrestricted access to food and water, with attendance by veterinary doctors and daily inspection. Study inclusion criteria for rabbits were based on general well being status, namely normal food and water ingestion, with absence of self-mutilation and weigh loss.

*Corresponding author: Humberto S Machado, Department, Centro Hospitalar do Porto, Largo Abel Salazar, 4099-001 Porto, Portugal, Tel: 351 935848475; Fax: 351 220900644; E-mail: hjs.machado@gmail.com

Received May 28, 2014; Accepted August 05, 2014; Published August 10, 2014 Citation: Machado HS, Sá P, Nunes CS, Couceiro A, da Silva ÁM, et al. (2014) Spontaneous One-Lung Ventilation Increases the Lung Inflammatory Response: An Experimental Pilot Study. J Anesth Clin Res 5: 428. doi:10.4172/2155 6148.1000428

Copyright: (c) 2014 Machado HS, et al. This is an open-access article distributed under the terms of the Creative Commons Attribution License, which permits unrestricted use, distribution, and reproduction in any medium, provided the original author and source are credited. 
Citation: Machado HS, Sá P, Nunes CS, Couceiro A, da Silva ÁM, et al. (2014) Spontaneous One-Lung Ventilation Increases the Lung Inflammatory Response: An Experimental Pilot Study. J Anesth Clin Res 5: 428. doi:10.4172/2155-6148.1000428

Page 2 of 5

\section{Study groups}

This study was conducted as a prospective randomized animal experiment; with four groups with five rabbits each being studied. Group 1 and 2 had spontaneous OLV during 20 and 75 minutes, respectively; Group 3 and 4 had spontaneous two-lung ventilation (TLV) during 20 and 75 minutes, respectively. All rabbits received 2 litter/minute fresh gas mixture of oxygen and air. Since the TLV group was not submitted to any thoracic instrumentation, just receiving anesthesia as the OLV group, this was assumed to represent the control group.

\section{Instrumentation}

The rabbits were anesthetized with intramuscular ketamine 50 $\mathrm{mg} / \mathrm{kg}$ (Imalgene ${ }^{\circledR}$, Merial Laboratorios, S.A., and Spain) and xylazine $4 \mathrm{mg} / \mathrm{kg}$ (Rompum ${ }^{\circledR}$, Bayer, Leverkusen, Germany). Anaesthesia maintenance was attained with half the initial dose of ketamine and xylazine every 20 minutes. The anterior region of the neck and the abdomen were shaved, with a $2 \mathrm{~cm}$ vertical midline incision being made through the anterior cervical region; after exposing the trachea, an incision was made to allow the introduction of a 2.5 tracheal tube to be connected to a spontaneous breathing system (Jackson-Rees type) with 2 litters per minute flow of a fresh oxygen/air mixture.

\section{Monitoring}

During the procedure non-invasive monitoring was used to monitor heart rate (HR) and peripheral arterial saturation $\left(\mathrm{SpO}_{2}\right)$ (Nellcor Oximax N600X ${ }^{\circledR}$,Tyco Healthcare group LP, Nellcor Puritan Bennett Division, Pleasanton, CA 94588, USA); respiratory rate (RR) was monitored by direct observation. First and last measurements were obtained at five minutes after setup and five minutes before the end of the procedure. We developed an OLV model using spontaneous ventilation in order to avoid pro-inflammatory situations previously described as the multiple hit hypotheses (such as mechanical ventilation, surgical manipulations and re-expansion/reperfusion). In all rabbits, a left subcostal incision was performed; In Groups 1 and 2 air injection $(10 \mathrm{ml} / \mathrm{kg})$ was administered through the left costal-diaphragmatic recess into the intra-pleural cavity. Left lung collapse was confirmed by visual observation through the centre of diaphragm (by way of its transparency), as was right lung spontaneous ventilation (Figure 1).

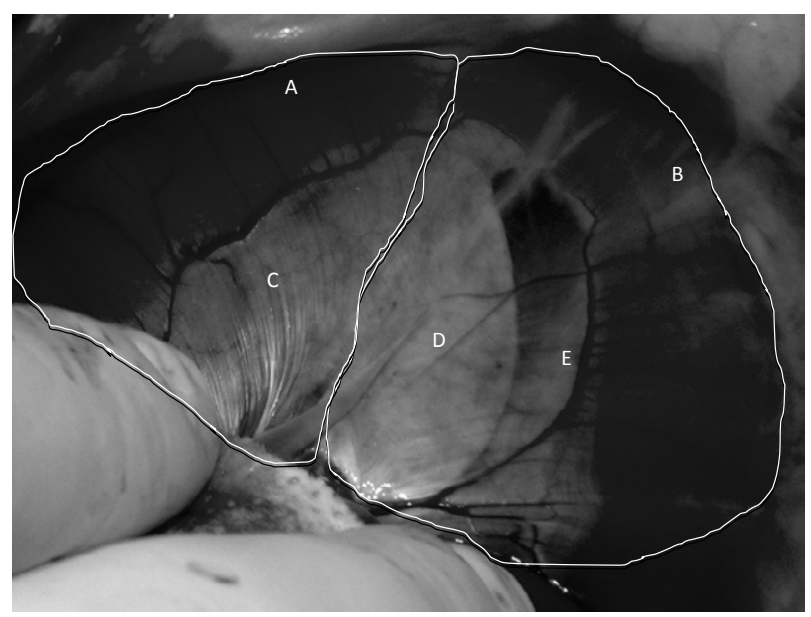

A-Basal view of right hemithorax, B-Basal view of left hemithorax, CInflatted right lung, D- Collapsed left lung, E-left pneumotorax

Figure 1: Rabbit Lung (diaphragmatic ventral aspect).
Groups 3 and 4 were maintained on spontaneous bilateral ventilation (control groups). The rabbit was identified as a suitable model for the study since its anatomy allows OLV due to the anatomic-physiological pleural separation of both sides of the thorax. At the end of procedure all rabbits were euthanized with ketamine $(100 \mathrm{mg} / \mathrm{kg})$ and xylazine $(8 \mathrm{mg} / \mathrm{kg})$, followed by section of abdominal aorta for exsanguination.

\section{Tissue samples}

The rabbits' lungs were harvested and fixed in $10 \%$ formaldehyde and embedded in paraffin for a light microscopy (LM) study. Three micra sections from the left and right lungs (superior, middle and lower lobe) were obtained from all rabbits. Lung sections were stained in haematoxylin and eosin.

\section{Histopathology}

An arbitrarily defined four level inflammatory score was assigned to the lungs depending on the intensity of inflammatory infiltrates in each lung plate: no inflammation, light, moderate and severe inflammation.

Infrequent inflammatory cells and/or inflammation confined to a few areas (corresponding to less than 15 cells per high magnification field of 40x) [8] were defined as a light inflammatory response. Multiple areas in the tissue or a large area of inflammatory cells (corresponding to an average of 16 to 25 cells per high magnification field 40x) [8] were defined as a moderate inflammatory response. Large multifocal areas of tissue with inflammatory cells or almost all areas of tissue affected (corresponding to more than 25 cells per high magnification field 40x) [8] were defined as severe inflammation. Thus, rabbits were classified as light, moderate or severe inflammatory responders according to the intensity of inflammation assessed by total plate visualization. Staff investigators who collected data during the procedure were aware of the group assignments. An independent and experienced pathologist (unaware of which subject was being evaluated) classified all plates accordingly to the criteria set.

\section{Statistical analysis}

The Resource Equation method [9] was used to determine if the sample size was appropriate for the experiment, considering a laboratory animal study with a controlled set-up. A sample size of 5 rabbits per group with a total of 4 groups $(n=20)$ were considered adequate for the questions being asked, resulting in an adequate error component ( $\mathrm{df}$ ) between 10 and 20 . Odds ratio (OR) was used as a measure of association. Kruskal-Wallis non-parametric test was used to compare variables between groups. Friedman test (Nonparametric two-way ANOVA) was used to compare variations within groups. Spearman's rho was used as a measure of correlation between the different variables and the level of inflammation. Pearson's chisquared test was used to test for independence in inflammation. The statistical hypothesis is that the occurrence of moderate inflammation is independent of the technique (OLV or TLV). A p-value $<0.05$ was considered statically significant. The Statistics Matlab ${ }^{\circledR}$ Toolbox from Mathworks, and Microsoft Excel 2013 were used for all calculations. Data is presented with median and range variables.

\section{Results}

All rabbits fulfilled the inclusion criteria for the study; daily visits to vivarium demonstrated animal wellbeing, with normal feeding, absence of self-mutilation, or weight loss. 
Citation: Machado HS, Sá P, Nunes CS, Couceiro A, da Silva ÁM, et al. (2014) Spontaneous One-Lung Ventilation Increases the Lung Inflammatory Response: An Experimental Pilot Study. J Anesth Clin Res 5: 428. doi:10.4172/2155-6148.1000428

\section{Weight, heart rate $(\mathrm{HR})$, respiratory rate $(\mathrm{RR})$, oxygenation $\left(\mathrm{SpO}_{2}\right)$}

The median weight was $1975 \mathrm{~g}(\min 1378$; $\max 3790)$ in the OLV Group and $1912.5 \mathrm{~g}(\min 1400 ; \max 2433)$ in the TLV Group, with no statistical difference between the two.

Table 1 summarizes values for all the parameters. During the procedure $\mathrm{SpO}_{2}$ significantly increased in both groups $(\mathrm{p}<0.05)$. In the OLV Group, $\mathrm{SpO}_{2}$ had a median increase of $4.5 \%$ and in the TLV Group $\mathrm{SpO}_{2}$ increased by $5.2 \%$, with no differences between the groups. Initial $\mathrm{SpO}_{2} \mathrm{HR}$ and $\mathrm{RR}$ values are not correlated with the level of inflammation. When considering all rabbits, only the percentage change in RR had a negative correlation with the level of inflammation $(\mathrm{R}=-0.512, \mathrm{p}<0.05)$.

\section{Lung inflammation}

Rabbits in Group 1 and 2 were found to be equally likely to have moderate inflammation $(\mathrm{OR}=1$, Chi-square $\mathrm{p}=0.53)$. The same was also found in rabbits from Group 3 and $4(\mathrm{OR}=1$, Chi-square $\mathrm{p}=0.53)$. Since the degree of inflammatory response was not influenced by the length of the procedure, we aggregated the rabbits in only two groups: those submitted to OLV (group 1 and 2-OLV Group, $n=10$ ) and those submitted to TLV (group 3 and 4-TLV Group, $n=10$ ), so as to analyse the influence of OLV versus TLV, independently of procedure duration. As expected, all rabbits had some degree of inflammation. The OLV Group showed moderate inflammation in 4 subjects, whereas the TLV Group only did so in 2 rabbits. Our hypothesis was that the occurrence of moderate inflammation was independent of the technique used (OLV or TLV), but this was rejected (Chi-square $\mathrm{p}<0.05)$. In the OLV Group, inflammation results were compared between left (collapsed) and right lungs; there was moderate inflammation in 4 of the left lungs, whereas only 2 right lungs presented moderate inflammation. This contradicts the hypotheses that the occurrence of moderate inflammation is independent of the lung being collapsed or being ventilated (Chi-square $\mathrm{p}<0.05)$. The inflammatory cells found in these plates were neutrophils and eosinophils; the proportion found showed approximately $75 \%$ eosinophils and $25 \%$ neutrophils (Figure 2 ).

\section{Discussion}

In our study, rabbits submitted to one-lung ventilation (OLV) had greater degree of inflammatory response than did animals submitted to two-lung ventilation (TLV); this fact was shown in more rabbits having moderate inflammation response in the OLV group. In OLV animals, the inflammatory response was more intense in the left lung (collapsed) than in the ventilated lung, suggesting that OLV is not an indifferent factor to the occurrence of more intense inflammation. However, moderate inflammation also appeared in TLV group, which may raise the possibility of a cause also present in the TLV rabbits, but

\begin{tabular}{|l|c|c|c|c|}
\hline & \multicolumn{2}{|c|}{$\begin{array}{c}\text { OLV } \\
\text { (One-lung ventilation) }\end{array}$} & \multicolumn{2}{c|}{$\begin{array}{c}\text { TLV } \\
\text { (Two-lung ventilation) }\end{array}$} \\
\cline { 2 - 5 } & $\mathbf{1}^{\text {st }}$ recording & Last recording & 1 $^{\text {st }}$ recording & Last recording \\
\hline HR, bpm & $190(120-235)$ & $197.5(125-235)$ & $152.5(125-205)$ & $163.5(130-225)$ \\
\hline RR, b/m & $85(56-95)$ & $92.5(50-100)$ & $82(61-88)$ & $90(60-95)$ \\
\hline SpO2, \% & $91(79-100)$ & $96(91-100)$ & $89(68-95)$ & $94.5(80-99)$ \\
\hline
\end{tabular}

Values are presented as mean (range). HR: heart rate; RR: respiratory rate; $\mathrm{SpO}_{2}$ : peripheral oxygen arterial saturation; bpm: beats per minute; $\mathrm{b} / \mathrm{m}$ : breaths per minute; OLV-One-Lung Ventilation; TLV-Two-Lung Ventilation. There is no statistical difference between the OLV and TLV groups with respect to the $1^{\text {st }}$ and last recordings, or percentage change for all three physical parameters.

Table 1: Physical parameters.
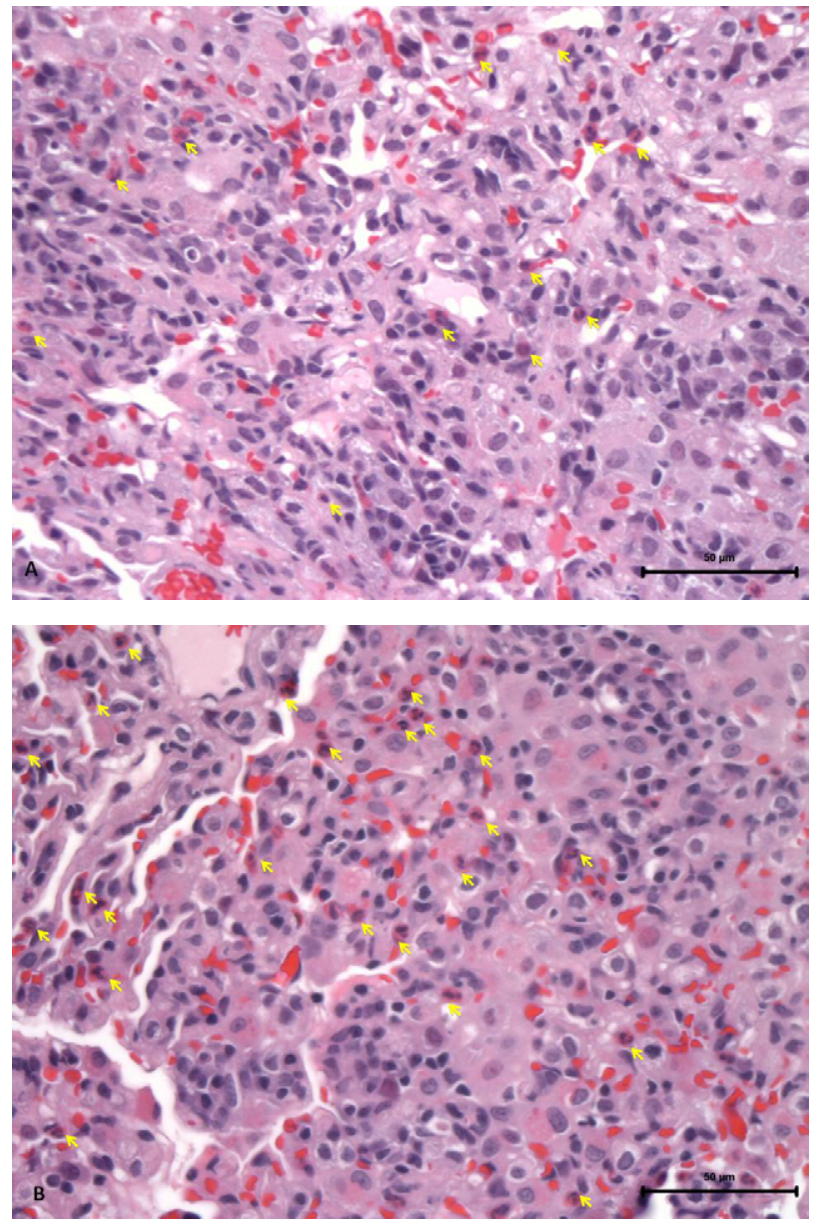

Legend: arrow-eosinophil

Figure 2: A-Light inflammation (12 eosinophils), B-moderate inflammation (23 eosinophils).

to a lesser extent than in OLV, possibly implicating a systemic effect in these findings. These facts draw our attention to a physiological situation that is present in the collapsed lung without any doubt, and might be present in the ventilated lung with lower intensity, namely areas of atelectasis. Based on this assumption, we may explain why even in a non-surgical spontaneous ventilation model (without interference of mechanical ventilation and surgical manipulation) the local acidic environment induced by atelectasis might induce inflammation, this finding being more pronounced when these areas are more extensive as is the case with whole lung collapse (such as in OLV). In this regard, one might assume that a major local event, such as a collapsed lung, might have the ability to induce a systemic effect affecting both lungs.

No high plateau pressures (barotrauma), no overdistension (volutrauma), nor the shear stress of repetitive opening (atelectotrauma) were present, since the model only included spontaneous ventilation with oxygen/air supplementation of 2 litters/minute. However, as demonstrated in some literature, when these factors were present the length of the procedure may be associated with a greater inflammatory response [10-12]. In all rabbits, spontaneous ventilation set up included a fixed volume of fresh gas flow of 2 litters per minute; this volume allowed visual control of spontaneous ventilation by means of JacksonRees balloon self-inflation and deflation observation. It was assumed that this fact implied that a certain degree of continuous positive airway 
pressure (CPAP) was applied to all animals, which could hypothetically prevent local atelectasis formation. Lung surgery has a 2-6\% mortality rate, according to the complexity of the surgical procedures [13]. At the present time, mortality rates have shifted away from the cardiac and surgical causes and are more related to pulmonary problems, such as infection and ALI in its most severe form, the acute respiratory distress syndrome (ARDS) [10,14]. The strongest predictors of ALI are related to the pre-operative condition of the patient, extent of lung resection, "injurious" mechanical ventilation and fluid therapy during the surgical procedure [13]. It is known that controlled OLV with higher tidal volumes $(10 \mathrm{ml} / \mathrm{kg})$ may produce a significant rise of inflammatory markers, including increased cellular infiltration [15]. Other causes of release of inflammatory mediators are hyperoxia and high levels of positive pressure at the end of inspiration [16,17]. In addition, studies showed that biochemical and histological lesions occur both in the collapsed and in the ventilated lung during OLV $[18,19]$. The ventilated lung may be subjected to a combination of volutrauma, hyperinflation, and hyperoxia that represents a potential source of oxidative stress and inflammatory response [20]. However, none of the situations previously described have been applied in this study. This draws attention to the possibility that the occurrence of moderate inflammatory response might be linked to the OLV status itself. Inflammation is characterized by profound changes in metabolic activity, tissue hypoxia and metabolic acidosis. These shifts in tissue metabolism are frequently associated with vasculitis and intense recruitment of various inflammatory cell types [21]. Furthermore, it is clear that oxygen supplementation in all subjects may increase the possibility of inflammation, since oxygen itself may induce the occurrence of atelectatic areas [22,23]. These areas are poorly ventilated and induce local hypoxia, with the consequent signalling of inflammatory mediators. However, both groups had oxygen supplementation, but the OLV group had higher moderate inflammation scores, implying that OLV clearly augments inflammatory response. The overall inflammatory response cell population found was composed of neutrophil and eosinophil leukocytes. However, in all plates the percentage of eosinophil leukocytes reached $75 \%$, which was an unexpected inflammation pattern. Eosinophils are involved in several inflammatory processes that imply a certain degree of pro-fibrogenic and pro-angiogenic activity, namely in some chronic allergic conditions such as asthma. This angiogenesis is often linked to hypoxic conditions present in inflamed tissues. Since eosinophils respond to hypoxia by up-regulation and other pro-angiogenic functions, this indicates that there may be a correlation between eosinophilic inflammation and hypoxia [23,24]. In our study, we did not suspect allergic conditions since all rabbits were considered healthy by the overall clinical analysis made at arrival and during quarantine time; with no abnormal clinical signs or symptoms being detected during the whole housing period. In addition, all rabbits had an official health certificate from the producer certifying the animals' wellbeing. Thus, eosinophilic predominance may be related to local hypoxic conditions. The results of this study show that some factors linked to the oxygen supply during OLV (and subsequent set up of oxygenation variability) may play a role not only in the occurrence of inflammatory response, but also on the type of cells encountered. Local hypoxia may have prompted inflammatory signalling, which might have been responsible for the appearance of either neutrophils and/or eosinophils. Considering all rabbits, the percentage of change in RR had a negative correlation with the level of inflammation $(\mathrm{p}<0.05)$; thus, it may be assumed that this increase in RR may lower systemic carbon dioxide levels and its correspondent contribution to acidity during inflammation.

The main findings in this study include:
- Spontaneous one-lung ventilation in a non-surgical, nonmanipulated lung, induces inflammatory changes in both lungs, with predominance in the collapsed lung.

- Atelectasis is present not only in the collapsed one-lung ventilated lung, but may also be present in two-lung ventilated subjects, however, with a more pronounced inflammatory response in the first.

- Inflammatory cellular infiltrates that result from a certain degree of lung atelectasis and local hipoxia, were predominantly eosinophilic in nature.

The conclusion of this study is that OLV (assumed as a major factor of atelectasis) is a relevant trigger for lung inflammation and, since no controlled ventilation was used, nor surgical manipulation of the lung was performed, this inflammatory response can be a direct physiological consequence. Study limitations were identified during our work and may contribute to plan further investigation. This spontaneous ventilation animal model was created to study the histological consequences of OLV. However, no previous studies were done that established a time limit for an experiment like the one carried out. In this regard, it was assumed that a seventy-five minute limit on the length of procedure was acceptable, as it might represent some similarity to the majority of thoracic procedures; however, further studies might contribute data regarding what is the ideal procedure duration in the study of the effects of OLV. Likewise, this study setup is not comparable to clinical OLV; in which positive pressure ventilation and lung exclusion using double-lumen tracheal tubes or bronchial blockers are used. Thus, further studies should be designed to allow the extrapolation to human clinical practice in order to know how to avoid consequences of atelectasis during and after anesthesia.

\section{Acknowledgement}

The authors would like to thank Mr. Costa e Silva for coordinating the housing and husbandry of animals, Mrs. Manuela Silva for help in laboratory tasks, and Dr. Ana Pinto and Dr. Madalena Costa for histological assembling and preparation.

The authors would like to thank Centro Hospitalar do Porto for the funding granted for the purchase of animals, animal food, and other husbandry expenses, as also the Anesthesia Department at Centro Hospitalar do Porto for funding the edition and publication of this study.

\section{Disclosures}

This study received funding from Centro Hospitalar do Porto (Largo Abe Salazar, 4099-001 Porto, Portugal) for logistic purposes, animal purchase, housing and husbandry. The Anesthesia Department at Centro Hospitalar do Porto (Largo Abel Salazar, 4099-001 Porto, Portugal) funded expenses regarding edition and publication. No funding was granted to any author.

\section{References}

1. Licker MJ, Widikker I, Robert J, Frey JG, Spiliopoulos A, et al. (2006) Operative mortality and respiratory complications after lung resection for cancer: impact of chronic obstructive pulmonary disease and time trends. See comment in PubMed Commons below Ann Thorac Surg 81: 1830-1837.

2. Boffa DJ, Allen MS, Grab JD, Gaissert HA, Harpole DH, et al. (2008) Data from The Society of Thoracic Surgeons General Thoracic Surgery database: the surgical management of primary lung tumors. See comment in PubMed Commons below J Thorac Cardiovasc Surg 135: 247-254.

3. Licker M, Fauconnet P, Villiger Y, Tschopp JM (2009) Acute lung injury and outcomes after thoracic surgery. See comment in PubMed Commons below Curr Opin Anaesthesiol 22: 61-67.

4. Eichenbaum KD, Neustein SM (2010) Acute lung injury after thoracic surgery. See comment in PubMed Commons below J Cardiothorac Vasc Anesth 24: 681-690.

5. Dulu A, Pastores SM, Park B, Riedel E, Rusch V, et al. (2006) Prevalence and 
Citation: Machado HS, Sá P, Nunes CS, Couceiro A, da Silva ÁM, et al. (2014) Spontaneous One-Lung Ventilation Increases the Lung Inflammatory Response: An Experimental Pilot Study. J Anesth Clin Res 5: 428. doi:10.4172/2155-6148.1000428

mortality of acute lung injury and ARDS after lung resection. See comment in PubMed Commons below Chest 130: 73-78.

6. Della Rocca G, Coccia C (2013) Acute lung injury in thoracic surgery. See comment in PubMed Commons below Curr Opin Anaesthesiol 26: 40-46.

7. Kozian A, Schilling T, Röcken C, Breitling C, Hachenberg T, et al. (2010) Increased alveolar damage after mechanical ventilation in a porcine model of thoracic surgery. See comment in PubMed Commons below J Cardiothorac Vasc Anesth 24: 617-623.

8. Lamagna C, Scapini P, A. van ZiffleJ, DeFranco AL, Lowell CA (2013) Hyperactivated MyD88 signaling in dendritic cells, through specific deletion of Lyn kinase, causes severe autoimmunity and inflammation.

9. Mead R (1988) The design of experiments. (Edn 1) Cambridge University Press, Cambridge, New York.

10. Baudouin SV (2003) Lung injury after thoracotomy. See comment in PubMed Commons below Br J Anaesth 91: 132-142.

11. Takenaka K, Nishimura Y, Nishiuma T, Sakashita A, Yamashita T, et al. (2006) Ventilator-induced lung injury is reduced in transgenic mice that overexpress endothelial nitric oxide synthase. See comment in PubMed Commons below Am J Physiol Lung Cell Mol Physiol 290: L1078-1086.

12. Jordan S, Mitchell JA, Quinlan GJ, Goldstraw P, Evans TW (2000) The pathogenesis of lung injury following pulmonary resection. See comment in PubMed Commons below Eur Respir J 15: 790-799.

13. Misthos P, Katsaragakis S, Theodorou D, Milingos N, Skottis I (2006) The degree of oxidative stress is associated with major adverse effects after lung resection: a prospective study. See comment in PubMed Commons below Eur J Cardiothorac Surg 29: 591-595.

14. Licker MJ, Widikker I, Robert J, Frey JG, Spiliopoulos A, et al. (2006) Operative mortality and respiratory complications after lung resection for cancer: impact of chronic obstructive pulmonary disease and time trends. See comment in PubMed Commons below Ann Thorac Surg 81: 1830-1837.
15. Licker M, Fauconnet P, Villiger Y, Tschopp JM (2009) Acute lung injury and outcomes after thoracic surgery. See comment in PubMed Commons below Curr Opin Anaesthesiol 22: 61-67.

16. Schilling T, Kozian A, Kretzschmar M, Huth C, Welte T, et al. (2007) Effects of propofol and desflurane anaesthesia on the alveolar inflammatory response to one-lung ventilation. See comment in PubMed Commons below $\mathrm{Br} J$ Anaesth 99: $368-375$.

17. Quinn DA, Moufarrej RK, Volokhov A, Hales CA (2002) Interactions of lung stretch, hyperoxia, and MIP-2 production in ventilator-induced lung injury. See comment in PubMed Commons below J Appl Physiol (1985) 93: 517-525.

18. Wilson MR, Choudhury S, Goddard ME, O'Dea KP, Nicholson AG, et al. (2003) High tidal volume upregulates intrapulmonary cytokines in an in vivo mouse model of ventilator-induced lung injury. See comment in PubMed Commons below J Appl Physiol (1985) 95: 1385-1393.

19. Tekinbas C, Ulusoy H, Yulug E, Erol MM, Alver A, et al. (2007) One-lung ventilation: for how long? See comment in PubMed Commons below J Thorac Cardiovasc Surg 134: 405-410.

20. Sakao Y, Kajikawa O, Martin TR, Nakahara Y, Hadden WA 3rd, et al. (2001) Association of IL-8 and MCP-1 with the development of reexpansion pulmonary edema in rabbits. See comment in PubMed Commons below Ann Thorac Surg 71: $1825-1832$.

21. Jordan S, Mitchell JA, Quinlan GJ, Goldstraw P, Evans TW (2000) The pathogenesis of lung injury following pulmonary resection. See comment in PubMed Commons below Eur Respir J 15: 790-799.

22. Nissim Ben Efraim AH, Eliashar R, Levi-Schaffer F (2010) Hypoxia modulates human eosinophil function. See comment in PubMed Commons below Clin Mol Allergy 8: 10.

23. Kilpatrick B, Slinger $P$ (2010) Lung protective strategies in anaesthesia. See comment in PubMed Commons below Br J Anaesth 105 Suppl 1: i108-116.

24. Karhausen J, Haase VH, Colgan SP (2005) Inflammatory hypoxia: role of hypoxia-inducible factor. See comment in PubMed Commons below Cell Cycle 4: 256-258.
Citation: Machado HS, Sá P, Nunes CS, Couceiro A, da Silva ÁM, et al. (2014) Spontaneous One-Lung Ventilation Increases the Lung Inflammatory Response: An Experimental Pilot Study. J Anesth Clin Res 5: 428 doi:10.4172/2155-6148.1000428
Submit your next manuscript and get advantages of OMICS Group submissions

Unique features:

- User friendly/feasible website-translation of your paper to 50 world's leading languages

- Audio Version of published paper

Digital articles to share and explore

Special features:

350 Open Access Journals

30,000 editorial team

21 days rapid review process

Quality and quick editorial, review and publication processing

Indexing at PubMed (partial), Scopus, EBSCO, Index Copernicus and Google Scholar etc

Sharing Option: Social Networking Enabled

- Authors, Reviewers and Editors rewarded with online Scientific Credits

Better discount for your subsequent articles

Submit your manuscript at: http://www.omicsonline.org/submission 